\title{
Comparison of Techniques for Measurement of Rumen pH in Lactating Dairy Cows
}

\author{
T. Duffield, ${ }^{1}$ J. C. Plaizier, ${ }^{2}$ A. Fairfield, ${ }^{3}$ R. Bagg,${ }^{4}$ G. Vessie,${ }^{4}$ \\ P. Dick, ${ }^{3}$ J. Wilson, ${ }^{1}$ J. Aramini,${ }^{1}$ and B. McBride ${ }^{5}$ \\ ${ }^{1}$ Department of Population Medicine, University of Guelph, \\ Guelph, Ontario N1G 2W1 \\ ${ }^{2}$ Department of Animal Science, University of Manitoba, \\ Winnipeg, Manitoba, R3T 2N2 \\ ${ }^{3}$ Floradale Feed Mill Ltd., Floradale, Ontario NOB 1V0 \\ ${ }^{4}$ Elanco Animal Health/Provel, Research Park Centre, \\ 150 Research Lane, Suite 120, Guelph, Ontario N1G 4T2 \\ ${ }^{5}$ Department of Animal and Poultry Science, \\ University of Guelph, Guelph, Ontario N1G 2W1
}

\begin{abstract}
Subacute rumen acidosis is thought to be a common condition in early lactating dairy cattle; however, diagnosis is difficult. There are currently only two techniques available for measuring rumen $\mathrm{pH}$ under field conditions: rumenocentesis and oral stomach tube. Sixteen rumen-fistulated cows were sampled in four sites of the rumen (cranial-ventral, caudal-ventral, central, and cranial-dorsal) with a rumen cannula. Rumen $\mathrm{pH}$ results were compared to those obtained at the same time with rumenocentesis and with an oro-ruminal (Geishauser) probe. Rumen fluid was obtained between 6 and 12 wk of lactation. Samples were analyzed for $\mathrm{pH}$, lactate, bicarbonate, sodium, potassium, and chloride. Rumen $\mathrm{pH}$ results were also compared to those obtained from 24-h continuous rumen $\mathrm{pH}$ measurement using indwelling rumen $\mathrm{pH}$ probes. Oro-ruminal probe samples had the highest $\mathrm{pH}$ values and the highest bicarbonate concentrations. Rumenocentesis samples had the lowest $\mathrm{pH}$ values and the lowest bicarbonate concentrations. Small differences in electrolyte concentrations were noted among rumen fluid collection techniques in the different rumen sites. The highest correlations of rumen $\mathrm{pH}$ were obtained between rumenocentesis and rumen cannulation (cranial-ventral), and between rumen cannulation (cranial-ventral) and the 24-h indwelling $\mathrm{pH}$ meter. Compared with samples obtained from the cranial-ventral rumen, rumenocentesis was more sensitive than the oro-ruminal probe in the measurement of low rumen $\mathrm{pH}$; both techniques were moderately specific. The most accurate field tech-
\end{abstract}

Received May 20, 2003.

Accepted August 28, 2003.

Corresponding Author: T. Duffield; e-mail: tduffiel@uoguelph.ca. nique was rumenocentesis. Improved field techniques are required for better on-farm diagnosis of subacute rumen acidosis.

(Key words: diagnosis, subacute rumen acidosis, rumenocentesis, Geishauser probe)

Abbreviation key: SARA = subacute ruminal acidosis.

\section{INTRODUCTION}

Rumen acidosis in dairy cattle is characterized by abnormally low rumen $\mathrm{pH}$ and is generally caused by a sudden increase in the consumption of or excess consumption of nonstructural carbohydrates, or decreased consumption of effective fiber. The periparturient depression of DMI, the transition to a high concentrate diet, and the nutritional demand of high milk production are factors that may contribute to increase the risk of ruminal acidosis in early lactation. By level of severity, the condition can be classified as peracute, acute, subacute, and mild (Blood and Radostits, 1989).

Subacute ruminal acidosis (SARA), the category of concern in this study, is a common and serious health and production problem in dairy herds, and has been linked to high herd culling rates (Jorgenson et al., 1993; Nordlund, 1996). Clinical signs of SARA vary and may include mild transient anorexia, intermittent diarrhea, dehydration, poor body condition, depression, decreased rumen motility, laminitis, unexplained abscesses, and decreased milk production (Blood and Radostits, 1989; Underwood, 1992; Nordlund and Garrett, 1994). Rumen $\mathrm{pH}$ values below 5.0 to 5.5 are considered abnormal and suggestive of either severe SARA, or possibly in combination with clinical signs, peracute or acute acidosis. (Blood and Radostits, 1989; Nordlund and Garrett, 1994), whereas rumen $\mathrm{pH}$ values of 5.6 to 5.8 are considered marginal (Nordlund and Garrett, 
1994). A diagnosis of SARA depends on the presence of abnormal low rumen $\mathrm{pH}$, as well as the persistence of clinical signs or an increased risk of culling.

It is believed that SARA is under-diagnosed by veterinarians because of diagnostic challenges associated with the lack of pathognomonic signs, diurnal fluctuations in rumen metabolism, and problems in obtaining representative rumen fluid samples (Jorgenson et al., 1993; Nordlund and Garrett, 1994). Common field techniques for collecting rumen fluid for SARA diagnosis include percutaneous needle aspiration (rumenocentesis) and oral stomach tube (Nocek, 1997). Previous studies suggest collecting samples 5 to $8 \mathrm{~h}$ after feeding of a TMR, or between 2 to $5 \mathrm{~h}$ after concentrate feeding in component feeding systems as rumen $\mathrm{pH}$ is expected to be lowest at these times (Nordlund and Garrett, 1994; Nocek, 1997).

Rumenocentesis is reported to be superior to the use of an oral stomach tube for the determination of rumen $\mathrm{pH}$ as the latter technique is susceptible to saliva contamination (Nordlund and Garrett, 1994). However, rumenocentesis is a more invasive technique involving surgical preparation of the centesis site, as well as chemical and physical restraint, and suffers from a risk of localized abscesses or peritonitis. An alternative technique developed by Geishauser (1993) utilizes a weighted oro-ruminal probe and suction pump, requires minimal time to perform, and is less invasive than rumenocentesis. The objective of the present study was to evaluate and compare the performance of rumenocentesis and oro-ruminal (Geishauser) probe with a view to identifying the most accurate technique for measuring rumen $\mathrm{pH}$. Rumen $\mathrm{pH}$ values obtained via rumenocentesis and oro-ruminal probe were compared to those obtained through a rumen cannula from different sites in the rumen and continuous electronic $\mathrm{pH}$ measurement in the ventral sac of rumen fistulated cows.

\section{MATERIALS AND METHODS}

\section{Study Animals}

This study was conducted in accordance with the University guidelines for animal research and with the approval of the University of Guelph Animal Care committee. Sixteen second- and third-lactation, pregnant, clinically healthy Holstein cows were selected for the study. Pregnancy status was confirmed using breeding history and rectal palpation. Animals were fitted with a rumen fistula approximately 10 to $12 \mathrm{wk}$ before their expected calving date, and were housed in individual metabolism tie stalls. Just before calving, cows were moved to individual maternity pens. Study animals were fed a TMR ad libitum twice daily at 0700 and 1300 h. At calving, animals were switched from a dry
Table 1. Ingredient composition (\% as fed) of the total mixed ration (TMR) for lactating cows (SE in parenthesis).

\begin{tabular}{lcc}
\hline Ingredient & $\%$ As fed (SE) & DM\% \\
\hline Corn silage & $42.6(2.7)$ & 35.2 \\
High moisture corn & $14.5-(1.4)$ & 72.0 \\
Mixed haylage & $23.3-(1.1)$ & 31.8 \\
Mixed hay & $5.7-(0.7)$ & 87.5 \\
Soybean meal & $6.4-(0.4)$ & 90.0 \\
Lactating cow supplement & $7.5-(0.5)$ & 92.0 \\
\hline
\end{tabular}

cow TMR to a lactating cow TMR with ingredients as shown in Table 1. The cows enrolled in this project were also used pre- and postcalving for a nitrogen balance study (Plaizier et al, 2000) and continued to receive the same lactating cow TMR while on the current study. The TMR was $50.4 \% \mathrm{DM}, 20.4 \% \mathrm{ADF}$, and $33.9 \% \mathrm{NDF}$, and had $1.56 \mathrm{Mcal} / \mathrm{kg}$ of $\mathrm{NE}_{\mathrm{L}}$, with more details reported by Plaizier et al. (2000). For the first 3 wk after calving, cows also received $1.8 \mathrm{~kg}$ of alfalfa hay once daily. Between 25 and $42 \mathrm{~d}$ after calving, $2 \mathrm{~kg}$ of high moisture corn was offered in an attempt to lower rumen $\mathrm{pH}$. Fresh water was provided ad libitum through the study period.

\section{Rumen pH Measuring Techniques}

Indwelling $\boldsymbol{p H}$ meter. Continuous $\mathrm{pH}$ monitoring was performed during the sixth week postcalving using an indwelling $\mathrm{pH}$ meter (Dado and Allen, 1993). A Sensorex Combi pH Electrode 450 CD (Sensorex, Stanton, CA) was placed through the rumen fistula and suspended in the ventral sac of the rumen. The electrode was protected by a wire shield and attached to a 0.5$\mathrm{kg}$ weight. Electrodes were connected to a Jenco Digital pH Transmitter model 691N (Jenco Inc., La Jolla, CA). The output of the $\mathrm{pH}$ transmitter was captured by a Universal Analog Input Multiplexer EXP-16 (Omega Engineering Inc., Stamford, CT) and DAS-8 analogue input board (Omega Engineering Inc., Stamford, CT). The software used for data capture was Labtech Notebook Version 10 (Laboratory Technologies Corporation, Wilmington, MA). A pH reading was taken once per second, averaged over each 60-s period, and then stored. The position of the $\mathrm{pH}$ electrode was checked daily in each cow, and the electrodes and $\mathrm{pH}$ transmitters were calibrated with pH 4 and 7 buffer solutions (Fisher Scientific, Fairlawn, NJ) at least once weekly. The continuous rumen $\mathrm{pH}$ data were summarized for each 24$\mathrm{h}$ period by calculating the average $\mathrm{pH}$, and the amount of time below $\mathrm{pH} 6$ and $\mathrm{pH}$ 5.6. After 1 wk of monitoring, the continuous $\mathrm{pH}$ monitoring equipment and indwelling $\mathrm{pH}$ probe were removed.

Fistulation (cannulation), oro-ruminal probe, and rumenocentesis. Insertion of the rumen fistula 
was performed using a modified surgical technique involving a rumen clamp (Duffield, 1999). Rumen fluid from 4 rumen sites (cranial ventral, caudal ventral, central, cranial dorsal) was obtained at each sampling using a cannula. Initially (for the first 6 cows), only the cranial ventral rumen was selected through the rumen fistula as a site for comparison to samples collected via rumeocentesis and oral probe sampling. However, for the final 10 cows on the study all 4 rumen sites were used. Extraction of rumen fluid for $\mathrm{pH}$ determination commenced during wk 6 postcalving and continued through to wk 12. The fluid was collected with a solid, tube-like probe containing rows of small holes on the end (Geishauser, 1992). The probe connected via hose and coupler to the same siphoning device used for the oral probe sampling. Consistency for the 4 rumen sites was obtained by following the same procedure at each collection. The cranial-ventral rumen was collected by inserting the probe at a $60^{\circ}$ angle toward the front feet through the fistula and the caudal-ventral rumen was sampled by inserting the probe at a $60^{\circ}$ angle toward the back feet through the fistula. The central rumen was sampled by advancing the probe nearly horizontally through the fistula site at a $90^{\circ}$ angle to the fistula and no further than the midline of the cow. The cranialdorsal rumen sample was obtained by advancing the probe through the fistula toward the head and maintaining the probe as dorsal as possible but still being able to obtain fluid. Rumenocentesis was conducted a total of 4 times for each cow (wk 6, 8, 10, and 12). Rumen fluid was obtained via cannulation and oro-ruminal probe once per week (wk 6 to 12). Rumen fluid collection by all 3 techniques occurred at the same time of the day to facilitate appropriate comparisons. The order of extraction of the fluid samples from each animal using the various techniques was alternated weekly. Rumen fluid $\mathrm{pH}$ measurements of all samples were performed immediately using a Corning benchtop pH meter (Corning 220, Corning Inc., Corning, NY). All samples were frozen for subsequent laboratory analyses of rumen electrolytes, bicarbonate and lactate. $\mathrm{Ru}-$ men fluid was analyzed at the Animal Health Laboratory of the University of Guelph. A bicarbonate system reagent (cat. no. 102050, Boehringer Mannheim, Mannheim, Germany), were used to determine concentration of the respective analyses with the BM/Hitachi 911 analyzer (Boehringer Mannhein). Ion selective electrodes for $\mathrm{Na}, \mathrm{K}$, and Chloride (Cl) (Boeringer Mannheim/Hitachi 911) were used for those determinations, respectively. Total lactate was determined in rumen fluid and blood plasma using Kodak Ektachem DT Clinical Chemistry slides (Eastman Kodak Co., Rochester, NY) on a Kodak Electrachem DT60 analyzer (Eastman Kodak Co.).
Collection of rumen fluid via the weighted oro-ruminal probe has been previously described (Geishauser, 1993). Samples were divided into the first $200 \mathrm{ml}$ of rumen fluid and the second $200 \mathrm{~mL}$ of rumen fluid for comparison.

Rumenocentesis used the technique described by Nordlund and Garrett (1994) and involved the surgical preparation of the left flank at the level of the stifle and approximately 15 to $20 \mathrm{~cm}$ caudo-ventral to the costo-chondral junction of the last rib. All animals were sedated with 30 to $40 \mathrm{mg}$ of xylazine administered intravenously. A tail jack was applied for additional restraint. A 12.5-cm, 16-gauge needle was inserted into the ventral sac of the rumen and an aliquot ( 2 to $5 \mathrm{~mL}$ ) of rumen fluid was obtained.

\section{Statistical Analyses}

All statistical analyses were conducted using SAS (SAS Institute, 1999). Generalized linear models were used to investigate the effects of rumen site and sampling technique on rumen $\mathrm{pH}$, electrolytes, bicarbonate, and lactate. Other factors considered in these models included time of sample post feeding, order of sampling, stage of lactation, and the within-cow correlation between observations. From these models, least squares means by sampling site and technique were generated for all rumen fluid variables measured. Pearson correlation coefficients ( $r$ ) were generated between sampling techniques and rumen cannulation sites. Taking the rumen cannulation results from the cranial-ventral rumen as the standard for SARA diagnosis, the relative sensitivities and specificities of the oro-ruminal probe and rumenocentesis techniques were calculated. The accuracy of the rumen cannulation sample results (cranial-ventral site) in comparison to the indwelling $\mathrm{pH}$ meter results was also determined.

\section{RESULTS}

\section{General Results and Observations}

Rumen fluid samples were not obtained from some cows on some days because of either behavioral problems or health concerns. Two cows were sampled only during wk 6 because they were too difficult to restrain for rumenocentesis. Oro-ruminal probe sampling was discontinued on two occasions because of difficulty in passing the oro-ruminal probe and/or the presence of blood in the saliva. These cows were sampled in subsequent weeks. In addition, one cow had reduced feed intake for 24-h following the first sampling with the oro-ruminal probe, and two attempts to collect fluid during that sampling with the oro-ruminal probe had yielded no rumen fluid. Although this cow was also 
Table 2. Number of rumen fluid samples obtained from 16 Holstein dairy cows and evaluated for $\mathrm{pH}$, electrolytes and lactate and bicarbonate during the study for each sampling method or rumen site.

\begin{tabular}{lccc}
\hline Collection site/method & $\mathrm{pH}$ & $\begin{array}{l}\text { Electrolytes } \\
\text { and lactate }\end{array}$ & Bicarbonate \\
\hline Oral probe-1st 200 mL & 92 & 72 & 47 \\
Oral probe-2nd 200 mL & 90 & 72 & 46 \\
Rumenocentesis & 52 & 44 & 26 \\
Cranial ventral rumen & 95 & 77 & 47 \\
Caudal ventral rumen & 40 & 30 & 29 \\
Central rumen & 40 & 30 & 29 \\
Cranial dorsal rumen & 40 & 30 & 29 \\
Total & 449 & 355 & 253 \\
\hline
\end{tabular}

sampled via rumenocentesis, the discomfort was presumed to be associated with the oral probe sampling because of the difficulty in collection and the lack of swelling or heat around the centesis site. Postcollection problems with rumenocentesis were limited to the development of 1 to 2 small ( 1 to $2 \mathrm{~cm}$ ) nodular swellings in approximately $1 / 3$ of the cows. No short- or long-term adverse consequences to these skin nodules were noted.

Overall, 449 rumen samples were collected and assessed for $\mathrm{pH}$. Electrolyte and lactate analyses were performed on a randomly selected subset of samples $(\mathrm{n}=355)$ because budget limited analyzing all samples collected. Because the cows on this study calved at different times, there were $41 \mathrm{wk}$ of sampling for the entire study period. Analysis for bicarbonate was conducted for the final 22 wk of the study in conjunction with the addition of the other 3 rumen sampling sites, which involved 10 cows and 253 rumen samples. Table 2 illustrates the numbers of samples obtained with each method or sampling site.

\section{Rumen pH, Lactate, and Electrolyte Analysis Results}

Least squares means (adjusted for time of day and within-cow correlation) of rumen $\mathrm{pH}$, bicarbonate, lactate, and electrolytes (sodium, potassium, and chloride) by sampling technique and cannulation site are presented in Table 3. Mean bicarbonate, chloride, and $\mathrm{pH}$ levels were significantly $(P<0.05)$ lower for the second oro-ruminal probe sample compared to the first. Both rumenocentesis and rumen cannulation (central site) had significantly $(P<0.05)$ lower rumen $\mathrm{pH}$ values compared with the other sampling techniques and rumen cannulation sites. Mean bicarbonate levels were lowest for rumenocentesis and rumen cannulation (caudal-ventral and central sites). Lactate levels were generally low; their highest concentrations were obtained with the oro-ruminal probe. On average, rumen samples taken in the morning had significantly higher $(P$ $<0.05) \mathrm{pH}$ values $(+0.30 \mathrm{pH}$ units) compared to those obtained in the afternoon. Order of sampling did not significantly influence $\mathrm{pH}$, lactate, or electrolytes.

There were generally poor to moderate correlations of mean rumen $\mathrm{pH}$ values between rumen sampling techniques and rumen cannulation sites after adjusting for the time of sampling and within cow correlation (Table 4). The first 200-mL of oro-ruminal probe samples correlated poorly with both the rumenocentesis and cannulation samples. Respective correlation values associated with the second $200-\mathrm{mL}$ of oro-ruminal probe samples were substantially higher. Rumenocentesis demonstrated more consistent correlations between rumen cannulation sites; however, the correlation values were still generally low. Overall, the $\mathrm{pH}$ values obtained from oro-ruminal probe and rumenocentesis samples correlated best with those associated with the central and cranial rumen cannulation sites.

An explanatory model to account for rumen $\mathrm{pH}$ differences among sampling techniques and rumen cannulation sites revealed that bicarbonate, potassium, and chloride concentrations all significantly contributed to rumen $\mathrm{pH}$ values. Lactate and sodium were not significant factors in the model. Accounting for bicarbonate, potassium, and chloride negated the impact of time of day.

To evaluate the accuracies of the oro-ruminal probe technique and rumenocentesis in the diagnosis of SARA, in comparison to rumen fluid samples obtained through rumen cannulation (cranial-ventral site), $\mathrm{pH}$

Table 3. Least squares means of rumen fluid variables by sampling technique and rumen site for 16 Holstein dairy cows (adjusted for the time of sampling and within cow correlation).

\begin{tabular}{|c|c|c|c|c|c|c|c|}
\hline Rumen fluid variable & \multicolumn{2}{|c|}{ Oro-ruminal probe } & Rumenocentesis & \multicolumn{4}{|c|}{ Rumen cannulation } \\
\hline Bicarbonate $(\mathrm{mmol} / \mathrm{L})(\mathrm{n}=253)$ & $0.98^{\mathrm{a}}$ & $0.14^{\mathrm{b}}$ & $0.01^{\mathrm{c}}$ & $0.43^{\text {ad }}$ & $0.03^{\text {ce }}$ & $0.01^{\mathrm{c}}$ & $0.11^{\text {bde }}$ \\
\hline Lactate $(\mathrm{mmol} / \mathrm{L})(\mathrm{n}=355)$ & $1.20^{\mathrm{a}}$ & $1.19^{\mathrm{a}}$ & $0.51^{\mathrm{b}}$ & $0.66^{\mathrm{c}}$ & $0.37^{\mathrm{d}}$ & $0.63^{b c}$ & $0.63^{\mathrm{bc}}$ \\
\hline Sodium $(\mathrm{mmol} / \mathrm{L})(\mathrm{n}=355)$ & $100.5^{\mathrm{a}}$ & $97.1^{\mathrm{ab}}$ & $98.5^{\mathrm{ab}}$ & $98.2^{\mathrm{ab}}$ & $93.4^{\mathrm{b}}$ & $91.7^{\mathrm{b}}$ & $96.6^{\mathrm{ab}}$ \\
\hline Potassium $(\mathrm{mmol} / \mathrm{L})(\mathrm{n}=355)$ & $32.5^{\mathrm{ab}}$ & $32.8^{\mathrm{ab}}$ & $33.9^{\mathrm{ac}}$ & $33.6^{\text {ac }}$ & $31.0^{\mathrm{b}}$ & $30.4^{\mathrm{ab}}$ & $30.6^{\mathrm{a}}$ \\
\hline
\end{tabular}

${ }^{a, b, c, d}$ Values having different letter superscripts within each row were significantly different at $5 \%$ significance level. 
threshold values suggested by Nordlund (1996) were used. Only samples where all three sites were collected at the same time were used in this analysis. For each of the rumenocentesis comparisons there were a total of 51 paired samples available and a total of 89 paired samples were available for the comparison of the oralruminal probe samples to the cranial-ventral rumen. Nordlund (1996) considers rumenocentesis samples equal to or below a $\mathrm{pH}$ of 5.5 to be abnormal, and those between 5.6 and 5.8 to be marginal. Given the average differences in $\mathrm{pH}$ values among rumen samples obtained through oro-ruminal probe $(+0.35 \mathrm{pH}$ units $)$ and rumen cannulation (cranial-ventral site; $+0.33 \mathrm{pH}$ units) in comparison to rumenocentesis (Table 1), SARA threshold values were adjusted accordingly. Thus, the corresponding critical thresholds for a rumen cannulation sample (cranial-ventral site) were at $\mathrm{pH} 5.8$ and 6.1, and the critical thresholds for oro-ruminal probe samples were at $\mathrm{pH} 5.9$ and 6.2, respectively. As demonstrated in Table 5, the sensitivities associated with rumenocentesis in the diagnosis of SARA (using either threshold value) were higher than those associated with the oro-ruminal probe. Both techniques demonstrated moderate to good specificities. Overall, the rumenocentesis technique was more accurate in the diagnosis of SARA in comparison to the oro-ruminal probe.

The mean 24-h indwelling rumen $\mathrm{pH}$ meter results for all 16 cows at wk 6 are presented in Figure 1. As expected, mean $\mathrm{pH}$ values begin to drop from a maximum value of approximately 6.5 after the morning feeding and continue to decline through the afternoon feeding to a minimum value of below 5.5 in the evening. Indwelling $\mathrm{pH}$ meter summary results for the 16 cows during wk 6 of lactation are shown in Table 6. On average, there were over $2 \mathrm{~h}$ per cow per day and $1 \mathrm{~h}$ per cow per day during which rumen $\mathrm{pH}$ readings were below 6.0 and 5.6, respectively (Table 6).

Evaluation of the 24-h $\mathrm{pH}$ values in comparison to the point samples obtained through the various sampling techniques used in this study demonstrated that $\mathrm{pH}$ results obtained via rumen cannulation (cranial-ventral site) were most strongly correlated with the time below $\mathrm{pH}$ 5.6. Pearson correlations between point sample $\mathrm{pH}$ values and indwelling $\mathrm{pH}$ meter time $\mathrm{pH}<5.6$ were as follows: oro-ruminal probe (first sample), $r=$ -0.15 ; oro-ruminal probe (second sample), $\mathrm{r}=-0.31$; rumenocentesis, $\mathrm{r}=-0.43$; and rumen cannulation cranial-ventral site, $r=-0.68$, caudal-ventral site, $r=$ -0.61 , central site, $r=-0.35$, cranial-dorsal site, $r=$ -0.50 . Using time below a $\mathrm{pH}$ value of 5.6 as the standard, the sensitivity and specificity of rumen cannulation (cranial-ventral site) was determined (Table 7). Rumen cannulation (cranial-ventral site) in comparison to the $24-\mathrm{h}$ indwelling $\mathrm{pH}$ meter results was $100 \%$ specific. Sensitivity increased to a maximum of $50 \%$ as time below a $\mathrm{pH}$ value of 5.6 increased.

\section{DISCUSSION}

The results of this study demonstrate that rumen $\mathrm{pH}$ varies significantly among sites within the rumen and by on-farm sampling technique (oro-ruminal probe and rumenocentesis). On average, rumenocentesis samples were 0.44 and $0.35 \mathrm{pH}$ units lower than those of the first and second oro-ruminal probe samples, respectively (Table 3 ). These observations are consistent with the estimated difference reported by Keefe and Ogilvie (1997). In addition, the mean $\mathrm{pH}$ difference found between rumen cannulation (cranial-ventral) and rumenocentesis in this study (0.33) compares favorably with what has been reported previously (Garrett et al., 1999). Higher $\mathrm{pH}$ values in oro-ruminal probe samples have been attributed to saliva contamination, and recommendations for obtaining rumen fluid with this technique have included discarding the first $200 \mathrm{~mL}$ of fluid obtained. Results from this study support this recommendation as the mean $\mathrm{pH}$ value was 0.1 units lower for the second compared with the first oro-ruminal probe sample (Table 3 ). In addition, mean bicarbonate concentrations were significantly lower for the second com-

Table 4. Correlations of rumen $\mathrm{pH}$ among sampling techniques and rumen cannulation sites for 16 Holstein dairy cows (adjusted for the time of sampling and within cow correlation).

\begin{tabular}{|c|c|c|c|c|c|c|c|c|}
\hline & & \multicolumn{2}{|c|}{ Oro-ruminal Probe } & Rumenocentesis & \multicolumn{4}{|c|}{ Rumen cannulation sites } \\
\hline Probe & Second $200 \mathrm{ml}$ & 0.792 & 1 & 0.251 & 0.249 & 0.238 & 0.577 & 0.534 \\
\hline \multirow[t]{2}{*}{ Rumenocentesis } & & -0.058 & 0.251 & 1 & 0.472 & 0.378 & 0.420 & 0.451 \\
\hline & Cranial-ventral & -0.030 & 0.249 & 0.472 & 1 & 0.334 & 0.114 & 0.350 \\
\hline Cannulation & Cranial-dorsal & 0.401 & 0.534 & 0.451 & 0.350 & 0.005 & 0.463 & 1 \\
\hline
\end{tabular}


Table 5. Relative sensitivity and specificity of oro-ruminal probe (with discard of first $200 \mathrm{~mL}$ ) and rumenocentesis compared to rumen cannulation samples from the cranial-ventral rumen after adjusting for $\mathrm{pH}$ Least Squares Means.

\begin{tabular}{llll}
\hline & $\begin{array}{l}\text { Sensitivity } \\
\left(95 \% \mathrm{CI}^{1}\right)\end{array}$ & $\begin{array}{l}\text { Specificity } \\
\left(95 \% \mathrm{CI}^{1}\right)\end{array}$ & Accuracy $^{2}$ \\
\hline $\begin{array}{l}\text { Severe subacute rumen acidosis } \\
\text { Oro-ruminal probe (n = 89) }\end{array}$ & $25 \%(0,55)$ & $96 \%(92,100)$ & $51 \%$ \\
$\begin{array}{l}\text { Rumenocentesis }(\mathrm{n}=51) \\
\text { Marginal subacute rumen acidosis }\end{array}$ & $67 \%(13,100)$ & $96 \%(90,100)$ & $81 \%$ \\
$\quad$ Oro-ruminal probe $(\mathrm{n}=89)$ & $50 \%(22,78)$ & $79 \%(70,88)$ & $64 \%$ \\
Rumenocentesis (n = 89) & $87 \%(64,100)$ & $74 \%(61,87)$ & $81 \%$ \\
\hline
\end{tabular}

${ }^{1}$ Confidence interval.

${ }^{2}($ Sensitivity + Sensitivity $) / 2$.

pared to the first oro-ruminal probe sample. By contrast, rumenocentesis samples contained little to no bicarbonate. We have no good explanation as to why the central rumen site had the lowest rumen $\mathrm{pH}$. Perhaps this area has a higher concentration of ruminal VFA causing a somewhat lower $\mathrm{pH}$ in the fluid.

Correlations in $\mathrm{pH}$ between sampling techniques and within rumen sites were generally low (Table 4). For rumenocentesis, the strongest correlation was with rumen cannulation (cranial-ventral site). This is not unexpected as the centesis technique involves collecting a percutaneous sample from the cranial-ventral rumen. The oro-ruminal probe technique was best correlated with the central and cranial-dorsal rumen sites. Although the oro-ruminal probe has been reported to reach the ventral rumen (Geishauser, 1993), it appears that in this study the probe was likely more dorsal because the samples obtained from the probe correlated best with cranial dorsal and central rumen samples collected through the rumen fistula. It is possible that the probe did not completely penetrate the dense fiber mat.

As measured by the indwelling $\mathrm{pH}$ meter (Figure 1), results of this study support previous suggestions that the lowest $\mathrm{pH}$ values occur 5 to $8 \mathrm{~h}$ postfeeding (Nordlund and Garrett, 1994). The fact that rumen samples taken in the morning had significantly higher $\mathrm{pH}$ values than those obtained in the afternoon suggests that the latter time might be preferable for taking samples for SARA diagnosis. Interestingly, after accounting for the levels of bicarbonate, potassium, and chloride, time of day was no longer associated with rumen $\mathrm{pH}$. This suggests that the diurnal $\mathrm{pH}$ changes are due at least in part to salivation and the presence of strong ions in the rumen.

Among all sampling techniques, rumen cannulation (cranial-ventral site) best reflected the values obtained with the indwelling $\mathrm{pH}$ meter. This is encouraging as the cranial-ventral rumen is the site for rumenocentesis and the desired site for the oro-ruminal probe. The cranial-ventral rumen is also the place in the rumen where most mixing of rumen contents occurs. In the diagnosis of rumen $\mathrm{pH}$ values below 5.6, point samples collected by rumen cannulation (cranial-ventral site), in comparison to the indwelling $\mathrm{pH}$ meter, yielded no false positives but many false negatives. Sensitivity increased as the duration of low $\mathrm{pH}$ increased (Table 7). It seems reasonable to assume that the longer the $\mathrm{pH}$ is below 5.6, the more likely the animal is to have problems associated with low rumen $\mathrm{pH}$. Rumen $\mathrm{pH}$ as measured by the indwelling $\mathrm{pH}$ meter, serves as a reminder that point samples are indeed just a snapshot in time. More work is needed to more accurately refine threshold and duration values of low rumen $\mathrm{pH}$ values associated with health or digestive efficiency problems.

The relative sensitivity and specificity of rumenocentesis and oro-ruminal probe samples for the diagnosis of SARA were calculated using the cranial-ventral rumen cannulation as the standard (Table 5). Rumen cannulation (cranial-ventral site) compared well with the in-

Table 6. Indwelling $\mathrm{pH}$ meter 24-h pH readings taken from 16 Holstein dairy cows during wk 6 of lactation.

\begin{tabular}{lcclc}
\hline Variable & Mean & $\begin{array}{l}\text { Standard } \\
\text { deviation }\end{array}$ & Minimum & Maximum \\
\hline 24-h mean pH & 6.38 & 0.24 & 5.99 & 6.96 \\
24-h minimum pH & 5.58 & 0.34 & 5.02 & 6.16 \\
24-h maximum pH & 7.02 & 0.16 & 6.62 & 7.28 \\
Time below pH 6.0 (min) & 169 & 220 & 0 & 667 \\
Time below pH 5.6 (min) & 66 & 101 & 0 & 390 \\
\hline
\end{tabular}


Table 7. Performance of rumen cannulation point sample $\mathrm{pH}$ (cranial-ventral rumen) compared to time below pH 5.6 using continuous 24-h indwelling $\mathrm{pH}$ meter in 16 Holstein dairy cows during wk 6 postcalving.

\begin{tabular}{lll}
\hline Time below $\mathrm{pH} 5.6^{1}$ & Sensitivity & Specificity \\
\hline$>0 \mathrm{~min}$ & $11 \%$ & $100 \%$ \\
$\geq 60 \mathrm{~min}$ & $25 \%$ & $100 \%$ \\
$\geq 120 \mathrm{~min}$ & $33 \%$ & $100 \%$ \\
$\geq 180 \mathrm{~min}$ & $33 \%$ & $100 \%$ \\
$\geq 240 \mathrm{~min}$ & $50 \%$ & $100 \%$ \\
\hline
\end{tabular}

${ }^{1}$ Period of time when the indwelling $\mathrm{pH}$ reading was below 5.6.

dwelling $\mathrm{pH}$ meter results and is considered an accepted industry standard. Nordlund (1996) considers rumenocentesis samples equal to or below a $\mathrm{pH}$ of 5.5 to be abnormal and those between 5.6 to 5.8 to be marginal. Given the average differences in $\mathrm{pH}$ values among rumen samples obtained through rumenocentesis, oro-ruminal probe, and rumen cannulation (cranial ventral site), SARA threshold values were adjusted accordingly. For the diagnosis of marginal SARA, rumenocentesis was highly sensitive $(87 \%)$ but yielded a $26 \%$ false-positive rate. For severe SARA, the falsepositive rate fell to only $4 \%$ and the sensitivity declined to $67 \%$. By contrast, the oro-ruminal probe was poorly sensitive at both thresholds but had comparable specificities.

\section{CONCLUSIONS}

Subacute rumen acidosis is a common and serious health and production problem in dairy herds. The management of SARA depends in part on the availability of a reliable and practical field test. This study demonstrated that rumenocentesis is a better field test in comparison to the oro-ruminal probe for the measurement of rumen $\mathrm{pH}$. Due to its higher sensitivity at marginal SARA $\mathrm{pH}$ values ( $\mathrm{pH} 5.8$ ), we propose that rumenocentesis be used to rule-out rather than confirm SARA. However, the lower cutoff of $\mathrm{pH} 5.5$ could be used to confirm SARA because the specificity improves as rumen $\mathrm{pH}$ declines. The oro-ruminal probe technique is very likely confounded by saliva contamination, nevertheless, a low $\mathrm{pH}$ value using this technique should be considered highly suggestive of SARA. More standardized and consistent tests are required for the diagnosis of SARA on-farm. Despite some low $\mathrm{pH}$ values observed in this study, none of the cows developed clinical illness during the period of study. Suggested rumen $\mathrm{pH}$ guidelines for SARA need to be linked with either clinical signs, impaired health, reduced production or an increased risk of culling to be sure that these $\mathrm{pH}$ values truly represent a potential health risk or financial loss.

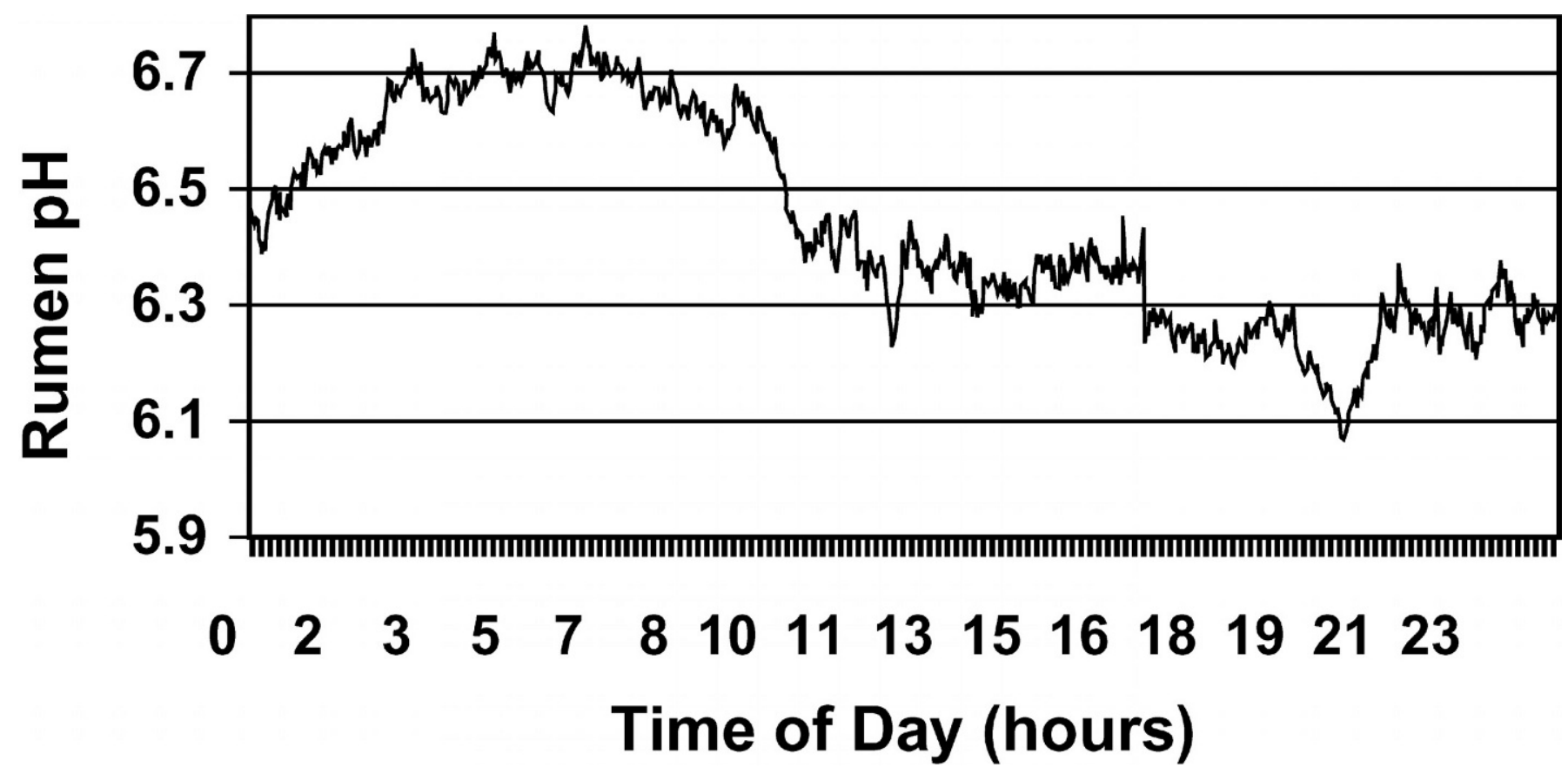

Figure 1. Mean continuous (averaged every minute) 24-h indwelling rumen pH meter results taken from 16 Holstein dairy cows during wk 6 of lactation. Cows were fed at 0700 and $1300 \mathrm{~h}$ 


\section{REFERENCES}

Blood, D. C., and O. M. Radostits. 1989. Veterinary Medicine. 7th ed. Balliere and Tindall, London, England.

Dado R. G., and M. S. Allen. 1993. Continuous computer acquisition of feed and water intakes, chewing, reticular motility and rumen pH of cattle. J. Dairy Sci. 76:1589-1600.

Duffield, T. 1999. A Fistful of rumen-A novel approach to rumen fistula surgery. Practice tips. Page 178 in Am. Assoc. Bovine Pract. Conf., Nashville, TN.

Garrett, E. F., M. M. Pereira, K. V. Nordlund L. E. Armentano, W. J. Goodjer, and G. R. Oetzel. 1999. Diagnostic methods for the detection of subacute rumen acidosis in dairy cows. J. Dairy Sci. 82:1170-1178.

Geishauser, T. 1992. Ein pansen-schraubtrokar fur erwachsene rinder. 1. Teil: seine verwendung als dauerfistel zur pansensaftentnahme fur forschungszwecke. Wien Tieraztl Mschr. 79:102-110.

Geishauser, T. 1993. An instrument for the collection and transfer of ruminal fluid and for the administration of water soluble drugs in adult cattle. Bovine Pract. 27:38-42.

Jorgenson, R. J., R. Erdman, M. Murphy, J. Foldager, P. Norgaard, P. Moller, P. H. Andersen, E. Nielsen, O. Osteras, P. Harmoinen,
P. Kodarik, K. Emanuelson, and E. Reinam. 1993. Rumen acidosis: areas of research. Summary of group discussion. Acta Vet. Scand. Suppl. 89:153-154.

Keefe, G., and T. Ogilvie. 1997. Comparison of oro-rumenal probe and rumenocentesis for prediction of $\mathrm{pH}$ in dairy cattle. Pages 168-169 in Proc. Annu. Conf. Am. Assoc. Bovine Pract.

Nocek, J. E. 1997. Bovine acidosis: Implications on laminitis. J. Dairy Sci. 80:1005-1028.

Nordlund, K. V. 1996. Questions and answers regarding rumenocentesis and the diagnosis of herd-based subacute rumen acidosis. Pages 75-81 in Proc. Annu. Conf. Am. Assoc. Bovine Pract.

Nordlund, K. V., and E. F. Garrett. 1994. Rumenocentesis: A technique for the diagnosis of subacute rumen acidosis in dairy herds. Bovine Pract. 28:109-112.

Plaizier, J. C., A. Martin, T. Duffield, R. Bagg, P. Dick, and B.W McBride. 2000. Effect of a prepartum administration of monensin in a controlled-release capsule on apparent digestibilities and nitrogen utilization in transition dairy cows. J. Dairy Sci. 83:2918-2925.

SAS User's Guide. 1999. Version 8.00 Edition. SAS Institute Inc., Cary, NC.

Underwood, W. J. 1992. Rumen lactic acidosis: Part 1. Epidemiology and pathophysiology. Compend. Contin. Educ. Pract. Vet. 14:1127-1133. 